\title{
The Myths of Brexit
}

\author{
Abstract \\ Cassirer's notion of myth and Langer's process philosophy are used to provide a novel perspective \\ upon how feelings were both expressed and organised in the Brexit referendum, showing how \\ multiple, overlapping organisations of feelings created a set of emergent rationalities. Political \\ parties and campaigns, the media and lived experience serve as analytic foci, and various feelings are \\ identified. It is concluded that the result was largely rational on its own terms, and that \\ understanding this is central to the social psychology of Brexit.
}

\section{Introduction}

A quick online search will identify many claims about Brexit that get characterised, either by supporters or opposers of Britain leaving the EU, as myths: it will produce an economic dividend for health, education and social care; it will cause a 'brain drain', or an exodus of migrant workers from the NHS; it will allow a future Labour government to end 'austerity'; and so on.

Characterising these claims as myths serves to question their accuracy. In what follows, whilst accuracy remains relevant, myth is used in the sense proposed by Cassirer (1946). In his analysis, myth is a symbolic form that gives expression to feeling. Myth orders and objectifies feeling: it arranges feelings in relation to objects, people and events. This is why myth sometimes uses fantasy. Stories of talking animals, magical places, dragons and demons do not describe actual circumstances. They express feelings such as awe, fear or hope, and organise them in relation to (putative) states of affairs.

Myth can be contrasted with science (another symbolic form). The character of scientific thought and reasoning depends largely upon the causal relations and empirical evidence it adduces. By contrast, the character of mythical thought and reasoning derives primarily from the feelings it expresses and organises. Importantly, however, it is not that science is wholly devoid of passion and feeling; nor that myth simply bears no relation to evidence. Rather, myth and science are two different modes of thinking and reasoning, one more obviously affective than the other, each of which serves different functions.

A prominent function of mythical thinking is its role in politics. Cassirer's magisterial historical survey demonstrates that every enduring political settlement contains a mythical element: for example, that one social group is inherently superior to others, or has a divine right to certain privileges. Nevertheless, in certain times or places, mythical thinking becomes more prominent or more influential. In social psychology, the 'just world hypothesis' (Lerner, 1980) - the idea that life is morally fair and 'people get what they deserve' - identifies a political myth. Claims that we live in a just world function primarily to neutralise feelings of indignation or anger caused by injustice, rather than by invoking demonstrable truths.

So myths implicate a style of thinking and reasoning that largely functions to express and organise feelings, and which can be politically influential. Importantly, myths often function pre-reflectively so that their influence at least partially eludes conscious reflection. To better understand this we can turn to a philosopher greatly influenced by Cassirer: Suzanne Langer.

In Langer's (1967, p.22) process philosophy "the entire psychological field .. is a vast and branching development of feeling". That is, both (what we call) cognition and (what we call) emotion are in 
some measure outcomes of feeling. Feeling, then, is not simply equivalent to emotion. Alongside those we recognise as emotional feelings (the buoyant limbs of elation, the churning stomach of fear) sit a range of typically subtler, more continuous, less intense feelings: of connection, dissociation, disjunction, obstruction, tension, strain, release, flow and "the very interesting sense of rightness that closes a completed thought process" (ibid, p.147). We can call these feelings of knowing (Cromby, 2015). They are no less influential than emotional feelings, and they too function to motivate, guide and direct reasoning. Their continuous relevance means that all thinking is actually felt thinking.

Whilst emotional feelings and feelings of knowing can differ phenomenologically, in terms of their typical qualities (intensity, duration, location, character), they also shade across, each into the other, with feelings such as excitement, impatience and confidence straddling between them. Feeling confident is part of 'knowing' that a 'completed thought process' is correct, just as feeling impatient is part of 'knowing' that something is unreasonable. Feeling shapes thinking by supplying valences and tendencies that motivate engagement, confer relevance, suggest direction and constitute judgement. But we often fail to notice this, because we remember the discursive contents of thought far more readily than we recall the ineffable feelings that prompted, connected and evaluated them. This helps explain why the influence of myths is often pre-reflective, although other factors contribute.

\section{The Myths of Brexit}

Brexit has a totemic status and magical connotations that both suggest the influence of myths: for example, that simply leaving the EU will secure jobs, end immigration, boost investment, raise living standards, make housing affordable, or wind back the cultural clock. Psychologically, the expression and organisation of feeling are frequently thoroughly entangled (since expression simultaneously reflects prior organisation and anticipates future influence). Nevertheless, to better understand how mythical thinking contributed to Brexit it will help to first identify the feelings the vote expressed, and then consider how those feelings were organised.

\section{Brexit: feelings expressed}

To trace the feelings Brexit expresses, insights can be gleaned from economics, social and public policy, and political theory. A common theme in these writings involves emotional feelings of anger and resentment, and feelings of knowing that one is 'left out' or 'left behind'. These feelings are typically connected to the inequality and regional disparities of recent decades. Economist Ann Pettifor (2017, p.127) claims that:

"the 'Brexit' vote is but the latest manifestation of popular dissatisfaction with the utopian ideal of autonomous markets beyond the reach of regulatory democracy. Brexit represented the collective, if (to my mind) often misguided, efforts of those 'left behind' in Britain to protect themselves from the predatory nature of market fundamentalism."

Pettifor links the Brexit vote to the deregulation of the UK financial sector since the 1970's, part of a series of changes which "underpinned the structures and operation of an increasingly globalised, autonomous, self-regulating market in finance, trade and labour" (op.cit.). These changes created the conditions for the global slump which began in 2007. Whilst this economic crisis itself prompted nationalist, populist and protectionist movements, subsequent so-called 'austerity' policies further contributed. These policies compounded the effects of economic strategies implemented over the previous 40 years which were already "enriching the $1 \%$ while shrinking labour's share of income..", and which "..resulted in rising inequality and lit a still smouldering fuse of popular resentment. Resentment made most explicit in the Brexit vote" (p.130). Illustrating this, McKenzie (2017a) 
gathered ethnographic data in East London before and during the Brexit referendum, and afterwards in Nottinghamshire. She describes how participants in both studies expressed anger at the marginalisation and unequal treatment of their working class communities, although for many this anger was coupled with apathy because "we can't change anything" (p.204)

Related arguments appear in political theory. Kagarlitsky (2017, p.114) characterised the Brexit vote as "a watershed event that marked the collapse of the cultural and psychological barriers that guaranteed the immutability of the neoliberal order". The economic changes Pettifor describes are elements within a broader political shift over recent decades, across the EU and other industrialised regions and countries, to a neoliberal form of capitalism. Neoliberalism includes financial deregulation; a shrinking of the state to focus on supposed 'core' activities of maintaining order and ensuring market functionality; and corresponding cuts in, and privatisations of, health, education and welfare services. Neoliberalism is associated with rising social inequality, precarious work (e.g. zero hours contracts), and the increasing concentration of power and resources amongst wealthy elites. Psychologically, it positions people less as citizens, and more as individual buyers and sellers (of labour power, goods and services) within an increasingly unfettered market.

Neoliberalism was implemented in the UK under successive Conservative governments from 1979, and continued under 'New Labour' from 1997 onwards. It came to dominate the EU, and Kagarlitsky identifies the 1992 Maastricht Treaty as the device that created "a new prison of nations, where any attempt to overcome neoliberalism is an attack on the constitutional order" (p.114). Hence, for Kagarlitsky the Brexit vote "was a rebellion against the neoliberal project but also no less a popular uprising against Britain's own ruling elites" (p.111). It took its particular form, he argues, because many left-wing movements aligned themselves with neoliberalism, allowing nationalist forces such as the United Kingdom Independence Party (UKIP) to channel discontent.

Jessop (2017) makes similar points in his argument that an overlapping series of enduring political and economic crises jointly created the circumstances that produced majority support for Brexit. He identifies an economic crisis, together with an associated crisis in the legitimacy of nation states, that began in the mid-1960's as trade became increasingly global. Growing internationalisation rendered national governments increasingly ineffectual, unable to intervene on behalf of citizens even where the will existed. With particular respect to the EU, these crises combined with others created by the relative dominance of Germany, and a recent series of migrant and refugee crises. These tensions were further exacerbated by the rise of the East Asian economies, and the corresponding shift of power and influence this produced. Consequently:

"The ever more visible polarization of wealth and income, noted increasingly even in neoliberal circles .. is generating popular discontent and corresponding measures to monitor the population, insulate government from popular demands for economic and social justice, encourage divide-and-rule tactics to this end, and, where necessary, repress dissent. (Jessop 2017, p.135)

Notably, Kagarlitsky's analysis identifies something hopeful in the Brexit 'rebellion': that independence from the EU would give greater freedom (in trade, social and legal affairs), or that government money no longer being paid to the EU would instead be spent on public services. Hopeful feelings were relevant for some who voted 'leave': in McKenzie's (2017a) data, there was hope about Brexit amongst her London participants, but not in Nottinghamshire. That many of these hopes flowed from mythical thinking does not diminish their relevance. 
So the Brexit vote expressed various feelings: of anger, resentment, discontent and hope, of feeling left behind or left out. These feelings were engendered by, or responding to, decades of growing injustice and inequality. In the popular imagination, as in many academic analyses, feelings particularly emotional feelings - get equated with irrationality. We make rational decisions and hold rational beliefs, in which case feelings are excluded: or we do not, in which case feelings contribute. Yet it seems perfectly rational to express anger at widespread and growing inequality and injustice. Likewise, feelings of being left out or left behind, far from being irrational, might simply reflect the circumstances neoliberalism has created. Taking a sociological perspective on the Brexit vote, Lianos (2017) argues that self-identity traumas and failures of respect, caused by material dependency and exclusion, produced feelings of revenge and contempt that actually embody "collective intelligence at its strongest" (p.293).

Nevertheless, the Brexit vote did express some feelings with a distinctly troubling relationship with rationality. Gietel-Basten (2016) notes that the UK population has been growing, and that - whilst this reflects a relatively high birth-rate - immigration has also contributed. Political strategies designed to divide and rule, as Jessop (2017) puts it, have long exploited the ready visibility of migrants (skin colour, language, accent, dress, religious observance, culinary preference etc.) to divert feelings of resentment from powerful elites. These historically embedded tendencies - an enduring theme of right wing tabloids - were mobilised in relation to the Brexit vote so that "the message that immigration was straining infrastructure and public services fell on receptive ears" (Gietel-Basten 2016, p.674). Feelings prompted by circumstances such as cuts in benefits and social services, the shortage of primary school places, the scarcity of affordable housing and the perilous state of the NHS - circumstances all traceable to neoliberal policy decisions - were instead directed toward immigrants. In this way, emotional feelings of anger and fear (of others, of difference, of change) were also expressed.

It is considerably easier to express anger or fear at something visible (immigrant bodies marked as threatening) than at something so intangible as a political and economic program - especially when this is encouraged by powerful figures. During the Brexit debate, Conservative politician Michael Gove (ironically, a former Minister of Education) claimed "People in this country have had enough of experts" (Mance, 2016). Arguably, what Gove inadvertently highlighted by denigrating specialist knowledge and professional acumen in this way was the extent to which the Brexit vote was not just about expressing feelings: it also reflected how these feelings were organised.

\section{Brexit: feelings organised}

The notion that feelings get organised in social relations is prominent in the work of cultural historian Raymond Williams. He wrote of 'structures of feeling', by which he meant "characteristic elements of impulse, restraint and tone: specifically, affective elements of consciousness and relationships: not feelings against thought, but thought as felt and feeling as thought" (Williams 1977, p.132). Structures of feeling are specific to times and places. They are a "living triangulation" between a person's biography (life experiences, upbringing, education), their current social position, and larger cultural or geopolitical forces (Highmore 2017, p.24). Whilst Williams' concept has been influential, it has also been criticised: because it is inexact, and because the 'structure' metaphor imports a rigidity that obscures the reactive dynamism between feelings and social relations (Burkitt, 2014). Here, the term 'organisations of feeling' reflects these criticisms: the word 'organisation' can be both verb and noun; it necessarily requires influences or actors to do the organising; and it highlights potentials that can be open-ended and flexible, as well as relatively fixed. 
With regard to Brexit, Highmore's (2017) cultural analysis concludes that the overall structure of feeling that engendered the referendum result was dominated by cynicism. The analysis presented here is more social psychological, primarily concerned with how the feelings of various social groups and strata were differentially organised. It suggests that mythical thinking about Brexit emerged from multiple organisations of feeling that overlapped and converged, albeit in somewhat inchoate ways. The discussion is organised with respect to three analytic foci: political parties and campaigns; the media; and lived experience. Their sequential consideration is, however, purely a presentational strategy, since in actuality lived experience is continuously shaped by political and media influences, just as media influence is neither wholly autonomous from the political sphere nor entirely reducible to it.

\section{Political Parties and Campaigns}

In their analysis of UKIP's rise, Ford \& Goodwin (2014) highlight important influences flowing from the two main UK political parties, Conservative and Labour. First, New Labour's dilution (since 1997) of its traditional left-wing stance to instead pursue pro-market (neoliberal) policies. Second, the responses of both main parties to immigration, and then to the recent financial crisis. Together, these influences created a large pool of disaffected voters that UKIP could exploit: by 2012 a record $40 \%$ of working class people strongly agreed that 'people like them' have no say in government (ibid, p.281.)

But specific political stances do not flow 'naturally' from disaffection. Rather, deliberate and sustained effort was needed to triangulate these feelings in ways that aligned them against the EU. Ford \& Goodwin describe how UKIP leader Nigel Farage implemented a 'fusion strategy' that intentionally merged the issues of Europe/the EU and immigration, whilst simultaneously linking these to radical right-wing tropes - of tradition and national identity, and hostility to, or mistrust of, elites. UKIP's strategy seized upon emotional feelings such as resentment at economic exclusion, suspicion of difference, and anxiety about cultural change. It organised these in relation to contrasting emotional feelings, for example hope for the future and nostalgia for the past, feelings it associated with notions of patriotism, tradition and 'Britishness'. Over time, this enabled UKIP to engender intellectual feelings of connection or association between a small set of what are, logically, separate (or at least separable) issues. Ford \& Goodwin (2014, p.282) observe that:

"the vast majority [of UKIP voters] combine hostility to the EU with strong concerns about immigration, dissatisfaction with the functioning of British politics and negative views about the performance of both Labour and Conservatives in immigration and the post-2008 financial crisis"

Alongside UKIP, leaving the EU was vocally promoted by significant numbers of Conservative MPs (including some cabinet ministers), and smaller numbers of Labour politicians. In the weeks before the referendum this took the form of overt campaigns aimed at the whole electorate. In relation to mythical thinking, two tactics are especially noteworthy.

First, the 'Vote Leave' campaign bus bearing the message "We send the EU f350million per week let's fund our NHS instead". It is impossible, now, to know how influential this claim was. But given enduring and widespread levels of public support for the NHS, coupled with regular reports that the NHS is in financial crisis, it seems reasonable to infer both that it exerted some influence and that it did so largely by organising feelings of loyalty, affection or gratitude towards the NHS, and conversely feelings of anxiety about its current state, in support of the 'leave' position. 
Second, the 'Vote Leave' campaign slogan 'let's take back control'. Each side in the referendum mobilised fear: vote remain, fear of the consequences of leaving the EU, often in economic terms; vote leave, fear of the consequences of remaining, notably in terms of future possible immigration from Turkey. Yet neither side "articulated a narrative that integrated fact-based and feelings-based arguments convincingly, and the Remain side, in particular, failed to connect to other arguments than those of economic benefits" (Forss \& Magro, 2016 p.16). That is, both sides emphasised fear, but neither managed to reconfigure the other's organisation of feeling. With this slogan, however, the 'leave' campaign also organised feelings of hope - feelings that the 'remain' campaign ignored.

\section{The Media}

Neither UKIP's 'fusion' strategy nor the 'leave' campaign in the referendum were independently influential: both gained considerable impetus from prior and concurrent media support. In journalism studies, the observation of a 'negativity bias' - a tendency toward polemic, at the expense of balanced judgement and fair critique - is almost universal. This bias is neither inherently right nor left wing (it was first identified in the 1960's within US media coverage critical of the Vietnam War). With respect to EU politics, Galpin \& Trenz (2017) argue that it creates a cynically inflected 'spiral of Euroscepticism' (de Vreese, 2007). This occurs because the selection of news items is value driven; because negativity correlates with increased distance from events; and because expectations of balance in domestic political reporting are not extended to EU politics. Since on average negativity suppresses reader interest in its target, it produces information deficits that render the public vulnerable to further polemic.

In the UK this effect may be particularly acute due to the increased influence, since the 1960's, of the Murdoch empire (Galpin \& Trenz, 2017). It was amplified in the referendum because the Daily Express took a Eurosceptic position, as did the Daily Mail. Consequently, most of the UK's print media were pro-Brexit and have for years been publishing stories jointly decrying immigrants, asylum seekers and EU bureaucracy.

The typical framing of these stories in relation to issues of national identity and sovereignty causes emotional feelings to predominate (Startin, 2015). Such stories seize upon feelings of familiarity, trust and respect within families, friendship networks and local communities, and align these feelings with political myths in ways that seemingly threaten identities. They do this by creating outgroups, which engenders hostility and fear: Startin's examples include the stereotyping of southern European countries in northern Europe, and the mobilisation of anti-German feelings in Greece. In a manner redolent of UKIP's 'fusion' strategy, then (and over a similarly extended period) media narratives repeatedly invoking national identity and sovereignty worked to associate biographies, current circumstances and political forces with feelings such as anger, fear and mistrust - encouraging organisations of feeling broadly hostile to EU legitimacy, and contributing to mythical thinking about Brexit.

Online social media amplify and repeat TV and newspaper stories and, increasingly, serve as news platforms themselves. In this regard, a widely-discussed concern is the so-called 'echo chamber' effect, wherein individuals read only information and commentary that supports views they already hold. Del Vicario, Zollo, Caldarelli, Scala, \& Quattrociocchi (2017) used network analysis techniques to map social dynamics amongst over 1 million Facebook users, and confirmed the emergence in relation to Brexit of two distinct communities corresponding to 'leave' and 'remain'. They combined this with sentiment analysis (automated content analysis of feeling terms) to show how the same news items elicited contrasting emotional responses from each community. 


\section{Lived experience}

From moment to moment, feelings get organised within dynamic, contingent combinations of economic, social and material circumstances: that is, by lived experience. Ford \& Goodwin (2014) provide insights into the organisations of feeling that lived experience was already creating, well before the Brexit referendum was staged. They show that feelings of being left behind were concentrated amongst older, white and working class voters, and that feelings about immigration, British identity, LGBT rights and Britain's relationship with the EU were similarly stratified. First, they describe some of the occupational, residential, educational and demographic changes of recent decades (summarised here in Table 1).

\begin{tabular}{|l|l|l|}
\hline & $\mathbf{1 9 6 4}$ & $\mathbf{2 0 1 0}$ \\
\hline Proportion of 'blue collar' workers & $\sim 50 \%$ & $30 \%$ \\
\hline Trades union membership & $40 \%+$ & $20 \%$ \\
\hline Living in council housing & $30 \%$ & $\sim 10 \%$ \\
\hline University educated & $\sim 12 \%$ & $\sim 40 \%$ \\
\hline Ethnic minority proportion of the electorate & $2 \%$ & $10 \%+$ \\
\hline
\end{tabular}

Table 1

These figures illustrate how in Britain "over the past fifty years .. a manufacturing-led economy gave way to a service-based and increasingly middle-class dominated society" (p.279). Different experiences of and opportunities for work were paralleled, for successive generations, by changing opportunities for education and increased exposure to ethnic minorities, and overall "a new class of financially secure and degree-holding middle class professionals came to dominate the national economy, society, politics and media" (op.cit). By contrast, however, "older, lower-skilled, blue collar workers .. have been pushed to the margins by rising inequality in incomes and prospects, the collapse of traditional industries, and the steady erosion of trade unions" (op.cit).

In short, the social and economic changes wrought by neoliberalism are not abstractions: they are concrete influences upon life chances, experiences and opportunities. It would be astonishing if differential exposure to these changes did not also differentially organise feelings in relation to social issues, and Table 2 - summarising data that Ford \& Goodwin extracted from the 2010 British Social Attitudes survey - demonstrates this.

\begin{tabular}{|c|l|l|}
\hline & Under 35 & Over 65 \\
\hline Immigration: negative economic impact & $41 \%$ & $52 \%$ \\
\hline negative cultural impact & $37 \%$ & $53 \%$ \\
\hline should be reduced a lot & $44 \%$ & $69 \%$ \\
\hline Being born here is very important to being British & $28 \%$ & $61 \%$ \\
\hline Same sex relations are always or mostly wrong & $11 \%$ & $42 \%$ \\
\hline Equal opportunities for LGBT have 'gone too far' & $17 \%$ & $50 \%$ \\
\hline The EU should have less/much less power than nation states & $36 \%$ & $73 \%$ \\
\hline
\end{tabular}


Table 2

So lived experience of changing economic and social circumstances, occurring simultaneously with changes in cultural norms, produced triangulations between biography, social positions and larger cultural forces that were stratified by age. They encouraged the organisation of feeling implied by Table 2: one that was often, but certainly not exclusively, concentrated amongst those who are older, poorer and less educated, and which was hostile to LGBT rights as well as the EU. This organisation of feeling provided fertile ground for mythical thinking.

Whilst qualitative academic analyses of people articulating their feelings about Brexit are so far rare, it is easy to find examples online. A short film called "Why They Voted Leave" (Sky News, 2016) presents a sequence of concise statements by (mostly older, and with just one exception white) English men and women from different backgrounds. The speakers deliver pithy, emotive assertions and extreme-case formulations broadly compatible with the organisation of feeling that Ford \& Goodwin imply, including:

"We're a dustbin.. we're a dustbin for foreign people"

"All our resources are pushed to the limits - schools, hospitals, NHS, everything"

"Our country's so small as it is, we should be concentrating on our children"

Amongst the few academic analyses thus far available, McKenzie (2017b) presents further insights from her ethnographic research in East London and the former Nottinghamshire pit villages. Discussing a group of women in East London, McKenzie describes how during the 2015 general election they were apathetic and disengaged because they saw themselves as "unimportant, powerless and invisible" (p.S274). But these same women saw the EU referendum as an exciting opportunity to have their voices heard, and were "overjoyed" by the result:

"Lisa: Do you think things will get better now, do you think us leaving the EU will make a lot of difference to people around here"

Anne: Not straight away no, but it will stop the amount of migrants coming here

Sally: Well its not going to stop me from being homeless [..]

Lisa: Do you think things might get even worse like they say on the news?

Sally: Worse .. I can't see how it can get much worse for me, but at least it's a change, its something" (pS275)

Again, we see (somewhat muted) hope here. Contrastingly, another London participant, Peter, had not voted in the referendum or any recent elections, and said the results meant nothing to him. McKenzie observes that "the overwhelming priority for Peter and for the women in the café was what affected them directly and locally" (p.S274). Gentrification and the lack of affordable housing dominated these local concerns: when asked to explain his lack of engagement, Peter "pointed up to the glass and chrome soaring into the sky 'will any of it stop all of this?'” (p.S273).

McKenzie characterises her London participants as angry, resentful, and either hopeful or (in Peter's case) afraid for the future. But amongst her Nottinghamshire participants, although many had also voted leave they were "far from optimistic about their prospects, or celebratory about what leaving would bring". Instead "sadness and loss" prevailed: 
Jan: I'd worked in that place since my kids went to school .. I was quite heartbroken when it shut down [..] Meritina Factory at the back of our house .. I mean that's not even a factory any more its just a warehouse now

Harry: Yes they don't bloody make owt anywhere now [..] there used to be hundreds going in there of a morning .. I don't see hardly anybody going in or out now apart from lorries in the middle of the bloody night (p.S276)

McKenzie's data illustrates how lived experience of differing locally dominant effects of neoliberalism - in London an unfettered housing market, in Nottinghamshire the decimation of traditional industry - encouraged somewhat different organisations of feeling. She is thoroughly respectful of her participants, insightfully observing that:

"the rhetoric of 'left behind' .. obstructs any genuine understanding of the structural nature of deindustrialisation, of class inequality, and of class prejudice .. it patronizingly dismisses the poor white working class as 'old fashioned' .. immobilized by a nostalgic longing for the past" (p.S277)

At the same time, McKenzie's exclusive focus upon working class people leaves the views of other groups unexamined. This is significant because in the Brexit referendum the eventual proportion of leave voters from the lowest two social classes was just $24 \%$, and most leave voters lived in the south of England (Dorling, 2017).

The mixed methods analysis by Flemmen \& Savage (2017) begins to address this concern. Working with survey and interview data gathered in 2008 for the National Child Development Study, they first conducted a quantitative analysis that identified three clusters of participants: one rich in cultural capital, one economically rich, and one poor and disenfranchised. Analysing interviews with respondents in the three clusters, they found that the clusters represented different forms of nationalism. Particularly noteworthy is the distinction between an 'imperial nationalist' repertoire concentrated amongst the economically and culturally rich, and an 'anti-establishment nationalist' repertoire that was more common amongst the disenfranchised:

Imperial nationalism:

"I don't have a problem with people from different nationalities who've been brought up here, who speak English, who behave like English people, who have the aspirations of English people .. If they don't have the same norms then I don't tend to regard them as British, you know, l'd rather kick them all out of the country but if they conform that's fine" (p.S251)

Anti-establishment nationalism:

"Its so lovely .. being British and seeing daffodils in the spring and, you know, I love all that. I couldn't live anywhere else.."

"I just see myself as British and don't think I'm very patriotic at all, no. If they asked me to stand up tomorrow and swear allegiance to the queen I don't think I would" (p.S254)

Relating these different nationalisms to the Brexit vote, Flemmen \& Savage suggest that feelings of hostility toward immigrants (imperial nationalism) were a driver of the 'leave' vote amongst the more affluent, and that such feelings were not - as some commentators seem to presume - the exclusive preserve of the working class. Their analysis accords with Dorling's findings whilst illustrating how mythical thinking about Brexit, for some, may have had a distinctly toxic nationalist character. 


\section{Discussion}

What does it mean to say that politics are emergent? Taking a process philosophical perspective, this paper has argued that politics emerges from organisations of feeling shaped, in part, by myths. Feeling is not simply internal to the individual: it is shaped by history, culture, social relations and material circumstance, at the same time that it is continuously enabled by fluid biological potentials. Times and places have their own organisations of feelings, organisations to which individuals contribute, but which also - far more pervasively, fundamentally and extensively - constitute individual experience.

This analysis has identified some of the important influences upon the multiple organisations of feeling from which emerged majority support for Brexit. It has shown how these organisations of feeling, whilst dynamically contingent upon variegated economic and social circumstances, were in no sense arbitrary. Rather, they were shaped by power relations relayed through political policies, positions, actions and inactions that stretch back, in some cases, for decades. Power was central to the Brexit vote: both the enduring lack of it; and its application - within the vagaries of lived experience, as refracted through the media, and as used by political parties and campaigns to selectively further some interests rather than others.

From this perspective, the question of whether the referendum result was 'rational' seems misconceived, in at least three ways. First, dominant power relations are intrinsically neither rational nor irrational - the criterion simply does not readily apply. Second, whereas evidence that emotional feelings shaped a decision is frequently taken as evidence of irrationality, we have seen that this is not necessarily accurate, and that in the Brexit vote emotional feelings influenced both sides. Third, the question seemingly implies something like a universal, trans-situational rationality against which the soundness of the vote could be sensibly judged. Yet the multiple, overlapping organisations of feeling identified here suggest that the Brexit vote was more representative of a set of political rationalities that were local and contingent, rather than global and universal.

In part this is because many people seem unlikely to have appreciated the extent to which their thinking about Brexit was actually mythical. Consider again the ' $£ 350$ million for the NHS' claim. It seems probable that many lacked either the education, knowledge, time, analytic skills, confidence or motivation to interrogate this assertion. Missing one or more of these things, they saw the claim asserted on a bus, displayed on TV, repeated by politicians, and discussed in the news. In such circumstances, judging its veracity in accord with the feelings it expressed and organised was, in a certain sense, rational - for how else could they make any judgement?

Simultaneously, understanding support for Brexit as locally, contingently rational accords with the way it recruited feelings of anger and fear in relation to immigration (feelings it then amplified, causing a steep increase in hate crimes). To be clear, prejudice and discrimination against immigrants is interpersonally offensive, ethically unacceptable and morally repugnant. But this does not mean that anger and fear repeatedly confected, amplified and targeted against immigrants by the right-wing media, feelings further organised by UKIP's fusion strategy, did not contribute - for some - to an organisation of feeling that supported the 'leave' position. This kind of mythical thinking about Brexit could be lived as factually based, respectable, legitimated by press and politicians and therefore legitimate, conventional and widely shared, and in all those senses perfectly 'rational' - at exactly the same time as, for those whose feelings were organised otherwise, its irrationality was self-evident.

In short, many who voted 'leave' acted rationally on their own terms. Some, no doubt, were simply motivated by prejudice, contempt and fear. But many others made the best judgement they could, 
based upon their experience - experience which often included understandable resentment and anger at years of growing inequality, injustice and marginalisation caused by neoliberal political policies - and in accord with (what they took to be) facts to which they had been exposed over many years.

The significance of this claim can be assessed by comparison with the established notion of 'bounded rationality' (Simon, 1955), which describes such phenomena in individualised cognitive terms: rationality is limited by available information, cognitive capacity and processing time. By contrast, the present analysis suggests that rationality is not so much bounded as contingent: upon temporal factors and available information, certainly; but also upon supra-individual organisations of feeling, forged in relations of power, that shape each and every 'rational' argument and which (variously) motivate people to resist, support, or ignore political policies, positions or debates.

This analysis also illuminates how mythical thinking can facilitate ideological manipulation. Importantly, though, it is not that we can or should aspire to a politics without feeling, nor even (if Cassirer is correct) a politics devoid of mythical thinking. For such a politics would never aspire to much, would lack vision, passion and ambition, and so would struggle to engage desires, recruit followers or mobilise support.

Nevertheless, considered psychologically or experientially (as opposed to programmatically, as coherent political system), mythical thinking could be one important way that ideology works. The recurring invocation, chaining and finessing of feeling, both incidentally and with deliberate intent, within practices of association and direction between feeling and signification, serves to triangulate feelings in ways broadly consonant with wider political stances. Along the way, deliberate ideological work such as UKIP's 'fusion' strategy can mobilise political myths ('immigration is bad'; 'leaving the EU will end immigration') that organise and express strong emotional feelings. Through repetition, and over time, the resulting organisations of feeling then come to include feelings of knowing that leaving the EU is desirable.

When this happens, whilst the myths themselves remain accessible, their pervasive effects upon thinking become largely imperceptible. This occurs because their associated organisations of feeling function both to confer attention upon some things instead of others, and to associate different topics and positions with particular valences - but they do this, as Langer suggested, largely prereflectively. Imperceptibility arises, then, not when myths are distant or remote, but precisely when individuals are so much within their grip that their associated feelings thoroughly permeate the indispensable 'background' (Shotter, 1993) of experience. Reasoning and thinking are then experienced, less as mythical, more as logical, rational and happily aligned with the values their corresponding organisations of feeling pre-reflectively embody. Appreciating this seems central to any adequate social psychological understanding of the Brexit vote.

Since neoliberalism is a global phenomenon, its effects - and those of the economic crisis it created are playing out internationally: Brexit yes, and Trump certainly - but also Austria, Hungary, Greece, the refugee 'crises' in the Mediterranean, and so on. Faced with this turbulence it is easy to fall into despair, yet - as we have seen - turbulence can foster hope. The task, then, is not just to bemoan how we have entered a 'post-truth' world ruled by emotions rather than facts. We should, undoubtedly, strive for accuracy in reporting and debate. We should also strive to better understand how feeling and fact are always already conjoined, in lived experience as in political debate, and deploy that understanding to pursue a politics where hope can become more than merely mythical.

Burkitt, I. (2014). Emotions and Social Relations. London: Sage. 
Cassirer, E. (1946). The Myth of the State. New Haven: Yale University Press.

Cromby, J. (2015). Feeling Bodies: embodying psychology. London: Palgrave.

de Vreese, C. (2007). A Spiral of Euroscepticism: the media's fault? Acta Politica, 42(2/3), 271-286.

Del Vicario, M., Zollo, F., Caldarelli, G., Scala, A., \& Quattrociocchi, W. (2017). Mapping social dynamics on Facebook: The Brexit debate. Social Networks, 50(Supplement C), 6-16.

Dorling, D. (2017). Brexit: the decision of a divided country. British Medical Journal, 354(3697).

Flemmen, M., \& Savage, M. (2017). The politics of nationalism and white racism in the UK. The British Journal of Sociology, 68, S233-S264.

Ford, R., \& Goodwin, M. (2014). Understanding UKIP: identity, social change and the left behind. The Political Quarterly, 85(3), 277-284.

Forss, K., \& Magro, L. (2016). Facts or Feelings, Facts and Feelings? The post-democracy narrative in the Brexit debate. European Policy Analysis, 2(2), 12-17.

Galpin, C., \& Trenz, H.-J. (2017). The Spiral of Euroscepticism: Media Negativity, Framing and Opposition to the EU. In M. Caiana \& S. Guerra (Eds.), Euroscepticism, Democracy and the Media: Communicating Europe, Contesting Europe (pp. 49-72). Houndsmills: Palgrave Macmillan.

Gietel-Basten, S. (2016). Why Brexit? The toxic mix of immigration and austerity. Population and Development Review, 42(4), 673-680.

Highmore, B. (2017). Cultural Feelings: mood, mediation and cultural politics. Abingdon, Routledge.

Jessop, B. (2017). The Organic Crisis of the British State: putting Brexit in its place. Globalizations, 14(1), 133-141.

Kagarlitsky, B. (2017). Brexit and the Future of the Left. Globalizations, 14(1), 110-117.

Langer, S. (1967). Mind: an essay on human feeling (Vol. 1). Baltimore: The Johns Hopkins University Press.

Lerner, M. J. (1980). The Belief in a Just World: a fundamental delusion. New York: Plenum Press.

Lianos, M. (2017). Brexit: should refusal (or even plate-smashing) be a sociological category? European Societies, 18(4), 291-294.

Mance, H. (2016, 3/6/2016). Britain has had enough of experts, says Gove. Financial Times.

McKenzie, L. (2017a). 'It's not ideal': Reconsidering 'anger' and 'apathy' in the Brexit vote among an invisible working class. Competition \& Change, 21(3), 199-210.

McKenzie, L. (2017b). The class politics of prejudice: Brexit and the land of no-hope and glory. The British Journal of Sociology, 68, S265-S280.

Pettifor, A. (2017). Brexit and its Consequences. Globalizations, 14(1), 127-132.

Shotter, J. (1993). Conversational Realities: constructing life through language. London: Sage Publications.

Simon, H. A. (1955). A Behavioural Model of Rational Choice. Quarterly Journal of Economics, 69, 99118.

Sky News. (2016). Brexiteer's Opinions: Why They Voted Leave. https://www.youtube.com/watch?v=rV-3U_YBPoE

Startin, N. (2015). Have We Reached a Tipping Point? The Mainstreaming of Euroscepticism in the UK. International Political Science Review, 36(3), 311-323.

Williams, Raymond (1977) Marxism and Literature. Oxford: Oxford University Press. 